\title{
Effects of $n-3$ fatty acid EPA in the treatment of depression
}

\author{
S. Keshavarz ${ }^{1}$, S. Jazayeri ${ }^{1}$, M. Tehrani-Doost ${ }^{2}$, M. Hosseini ${ }^{3}$, A. Djazayery ${ }^{1}$, M. Jalali ${ }^{1}$, H. Amini ${ }^{2}$ \\ and M. Chamari ${ }^{1}$ \\ ${ }^{1}$ Department of Nutrition and Biochemistry, School of Public Health, Tehran University of Medical Sciences, Tehran, \\ Iran, ${ }^{2}$ Roozbeh Hospital, Department of Psychiatry, School of Medicine, Tehran University of Medical Sciences, \\ Tehran, Iran and ${ }^{3}$ Department of Epidemiology and Biostatistics, School of Public Health, \\ Tehran University of Medical Sciences, Tehran, Iran
}

The objective of the present study was to assess the therapeutic effects of the $n-3$ fatty acid EPA in depression as compared with the antidepressant agent fluoxetine, the common drug for alleviation of this widespread disease.

Forty outpatients (twenty-seven females and thirteen males; age, 34.8 (SD 8.7) years; weight, 71 (SD 15.3) kg) with a diagnosis of major depressive disorder (by means of Diagnostic and Statistical Manual of Mental Disorders-intravenous ${ }^{(1)}$ ) were randomly allocated to receive daily either $1000 \mathrm{mg}$ EPA (plusEPA ${ }^{\circledR}$; Minami Nutrition, Edegem, Belgium) or $20 \mathrm{mg}$ fluoxetine for 8 weeks. The double-dummy technique was used to double-blind the study. Patients were assessed at baseline and at weeks 2, 4, 6 and 8 after initiation of the treatment. The change in the severity of depression (assessed by means of Hamilton depression rating scale (HDRS) ${ }^{(2)}$ ) was the primary outcome measure.

A two-way (time and treatment) repeated-measures ANOVA for HDRS was performed in twenty-eight patients who had completed the study. There were no significant differences between the two groups in controlling depressive symptoms throughout the trial and at the end point. The response rate ( $\geq 50 \%$ decrease in baseline HDRS) was higher in the EPA group (64\%), although not statistically different from that in the fluoxetine group $(57 \%)$.

Table. Severity of depression during the trial

\begin{tabular}{|c|c|c|c|c|c|c|c|c|c|c|}
\hline \multirow{2}{*}{$\begin{array}{l}\text { Time ... } \\
\text { Group }\end{array}$} & \multicolumn{2}{|c|}{ Baseline } & \multicolumn{2}{|c|}{ Week 2} & \multicolumn{2}{|c|}{ Week 4} & \multicolumn{2}{|c|}{ Week 6} & \multicolumn{2}{|c|}{ Week 8} \\
\hline & Mean & SD & Mean & SD & Mean & SD & Mean & SD & Mean & SD \\
\hline Fluoxetine & 29.0 & 6.9 & 23.5 & 6.9 & 20.6 & 7.0 & 18.6 & 5.7 & 15.5 & 6.2 \\
\hline EPA & 29.3 & 4.8 & 22.0 & 6.3 & 20.1 & 6.2 & 17.9 & 7.1 & 15.1 & 6.8 \\
\hline
\end{tabular}

For time: $P<0.001$ (repeated measures ANOVA). For time $\times$ treatment: $P=0.946$.

In this 8-week trial EPA was as effective as fluoxetine in controlling depressive symptoms. As EPA is a dietary supplement it may be more acceptable to patients than antidepressants.

1. Sadock BJ \& Sadock, VA (2003) In Kaplan \& Sadock's Synopsis of Psychiatry, p. 534. Philadelphia, PA: Lippincott, Williams and Wilkins.

2. Hamilton M (1960) J Neurol Neurosurg Psychiatry 23, 56-62. 